\section{Water Status of Sphagnum Peat and a Peat-Perlite Mixture in Containers Subjected to Irrigation Regimes}

\author{
Juha Heiskanen \\ The Finnish Forest Research Institute, Suonenjoki Research Station, FIN- \\ 77600 Suonenjoki, Finland
}

Additional index words. aeration, evaporation, matric potential, physical properties of soil, shrinkage, substrate, water retention

\begin{abstract}
Various irrigation treatments were studied to determine their effects on the water and aeration conditions of peat-based growth media and evaporation from these media. Low-humified sphagnum peat and a mixture of this peat and perlite (in containers) were subjected to three contrasting irrigation treatments in which the container capacity was used as a target water content. The more frequent the reirrigations and the lower the vertical position within containers, the higher the matric potential of the growth medium averaged. Furthermore, the higher the water content of the growth medium, the higher the mean evaporation was from the containers. Within each irrigation treatment, slightly more water (on average) evaporated from the peat than from the peat-perlite mixture. Due to higher water retention and shrinkage during drying, a pure peat growth medium may increase the risk of waterlogging and, hence, $\mathrm{O}_{2}$ deficiency for containerized plants if plants are irrigated frequently to container capacity. To prevent waterlogging and high water loss by evaporation, low-humified sphagnum peat can be irrigated relatively infrequently (especially at low evaporation rates) and thoroughly within a short time (especially at high evaporation rates).
\end{abstract}

In plant production, achievement and maintenance of favorable water and aeration conditions in growth media are crucial for crop growth and quality. For tree seedling production in open mineral soils, field capacity (at about $-10 \mathrm{kPa}$ matric potential) commonly has been used in irrigation control as the target for soil water content (Day, 1980; McDonald, 1984). Also, in production of containerized seedlings, a matric potential of $-10 \mathrm{kPa}$ often is used as the target limit for reirrigations (Landis et al., 1989). However, growth media, especially peat in containers, possess different physical properties and requirements for management practices than nonconfined mineral soils (Heiskanen, 1993a, 1995; Puustjärvi, 1975; Timmer and Armstrong, 1989; White and Mastalerz, 1966). In addition, when producing containerized seedlings, external conditions, species grown, irrigation methods, containers, and water retention characteristics between and within growth media vary (Heiskanen, 1993a, 1993b; Landis et al., 1989). Thus, the matric potential of the growth medium may vary between containers, even within

Received for publication 2 June 1994. Accepted for publication 23 Aug. 1994. Use of trade names does not imply endorsement of the products named nor criticism of similar ones not named. In addition to the referees selected by the editor, the manuscript was commented on by P. Aphalo and R. Rikala. The language of the manuscript was revised by J. von Weissenberg. The cost of publishing this paper was defrayed in part by the payment of page charges. Under postal regulations, this paper therefore must be hereby marked advertisement solely to indicate this fact. crop batches. Matric potentials up to the container capacity (about $-1 \mathrm{kPa}$ ) also may occur after reirrigations due to the percolation barrier at container bottoms (Landis et al., 1989; White and Mastalerz, 1966). However, only limited information is available concerning the effect of irrigation regime, which can vary in irrigation frequency and target water content, on the actual water and aeration conditions in containerized peat growth media. My aim was to determine the effects of various irrigation regimes, in which the container capacity was used as the target water content, on the water and aeration conditions of peatbased growth media in containers and on evaporation from these growth media.

\section{Material and Methods}

The growth media used in this study were pure, medium-grade peat (Vapo E, VAPO Corp., Jyväskylä, Finland) and a mixture of $33 \%$ coarse-grade perlite (Nordisk Perlite Corp., Copenhagen, Denmark) and $67 \%$ peat (v/v). The peat medium was light, lowhumified sphagnum peat, commonly used in Finnish tree nurseries. Particle size distribution for the pure growth media materials were determined from air-dried samples replicated three times using a mechanical sieving machine (Heiskanen, 1993b, 1993c). Water retention characteristics (water content vs. matric potential)for the media were determined based on the saturated volume (approximate volume of filled containers) from three replications using detailed procedures described by Heiskanen (1993b). Aeration was determined by air-filled porosity measurements. Air-filled porosity values for the matric potentials measured were obtained from water retention characteristics and were determined as total porosity minus water retention (Heiskanen, 1995; Puustjärvi, 1975, 1977).

The growth media were manually packed at a pressure of $10 \mathrm{~g} \cdot \mathrm{cm}^{-2}$ into polystyrene containers with average volumes of $285 \mathrm{~cm}^{3}$ (TA710; Lannen Corp., Iso-Vimma, Finland) (Heiskanen, 1993b, 1993c). For measuring the matric potential of the media, tensiometers were installed at three depths in each container (Fig. 1). The plantless containers were placed in a greenhouse with only artificial lighting and were subjected to one of three irrigation treatments: media were slowly hand-irrigated with tap water A) twice a day, B) once a day, or C) twice a week. A water content equal to or slightly lower than the container capacity (about -0.5 to $-1 \mathrm{kPa}$ ) was used as the target (Heiskanen, 1993a; White and Mastalerz, 1966). Evaporation from containers was determined gravimetrically by weighing the containers before and after reirrigations. The amount of water applied was about equal to the water loss due to evaporation between applications, and no excess water percolated through the containers. Both growth media were monitored in three containers during three consecutive experiments, during each of which each container was subjected to one of the three irrigation treatments using a fully randomized design. Thus, there were three replications $(n=3)$ of each medium-irrigation treatment combination and a total of 18 growth media in containers (two $\times$ three $\times$ two).

During the experiments, the matric potential in the growth media was measured every second hour using tensiometers and an automated measurement system (Heiskanen and Laitinen, 1992). In addition, air temperature at the surface of the containers was measured automatically. Evaporation from the containers was expressed as the rate per unit surface area of growth medium. Daily potential evapotranspiration (PET) was estimated from the water evaporation from an open glass pan

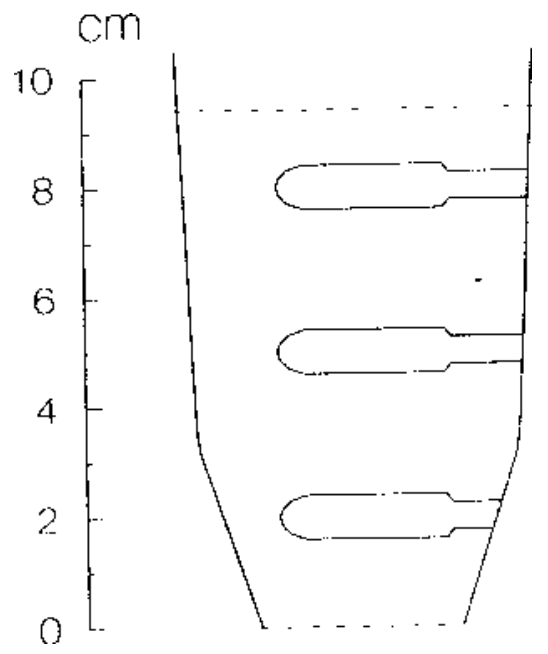

Fig. 1. Tensiometers position in containers during irrigation experiments. Dashed lines indicate the upper and lower limits of the growth medium. 
(depth, $8 \mathrm{~cm}$; height, $10 \mathrm{~cm}$ ). During the experiments, the mean PET was $5.3 \mathrm{~mm}$. Total radiation (wavelength 0.4 to $1.1 \mu \mathrm{m}$ ) was 45 to $50 \mathrm{~W} \cdot \mathrm{m}^{-2}$ under artificial lighting (day) at the surface of containers. At the same level, the temperature averaged between $32 \mathrm{C}$ day/25C night (Fig. 2).

Median values and cumulative frequencies were calculated for matric potentials within treatments (Heiskanen, 1995). To compare the differences between treatment means, oneand two-way analysis of variance (ANOVA) and Tukey's test were applied. When variances were unequal, Ftest and Tukey's pairwise comparisons also were used because the values obtained for significance were close to those achieved with the Brown-Forsythe test, which does not require equal variances.

\section{Results and Discussion}

The particle size distribution of the mixture components used (Table 1) and the desorption water retention characteristics (Fig. 3 ) of the mixtures were similar to those presented earlier for the same type of growth media (Heiskanen, 1993b, 1993c; Puustjärvi, 1977). The water retention of peat at desorption was greater than that of the peat-perlite mixture (Fig. 3). The shrinkage of peat at desorption was also markedly greater than that of the peat-perlite mixture. For example, between matric potentials -1 to $-5 \mathrm{kPa}$, the volumes of the peat and the peat-perlite mixture were $78 \%$ to $82 \%$ and $89 \%$ to $92 \%$, respectively, of the initial saturated volume.

Mean daily evaporation (4.7 to $6.9 \mathrm{~mm}$ ) from the containers differed significantly between irrigation treatments (two-way ANOVA for treatment $\times$ medium at $P<0.001)$ and decreased with a decrease in irrigation frequency (Table 2). In addition, in each irrigation treatment, water evaporated from peat slightly more than from the peat-perlite mixture (two-way ANOVA at $P=0.036$ ). Thus, the greater the water content in the growth medium, the greater the evaporation (Rikala, 1985). Within irrigation treatments, however, there was neither significant difference between the growth media (one-way ANOVA, Table 2) nor a significant growth medium $\times$ irrigation treatment interaction (two-way ANOVA at $P=0.930$ ). Evaporation from the free-water surface averaged less than that from the growth media in irrigation treatments $A$ and B. However, this was probably due mainly to ventilation, the properties of the glass pan, and the differing temperatures at the surfaces of peat and water (Vakkilainen, 1982). Due to the high temperatures, the evaporation rates achieved here were relatively large (mean 5.3 $\mathrm{mm} \cdot \mathrm{day}^{-1}$ ). In Finnish greenhouse culturing of containerized tree seedlings with daily irrigation, the daily evapotranspiration from peat growth medium is $\approx 2$ to $4 \mathrm{~mm}$ (Rikala, 1985). In the production of small containerized tree seedlings, transpiration usually forms only a minor part of the total evapotranspiration (Rikala, 1985). During drying, water availability and the transpiration of tree seedlings decrease (Landis et al., 1989; Langerud and
Sandvik, 1991; Timmer and Miller, 1991). Because the hydraulic conductivity of peat declines strongly during drying (Heiskanen, 1993c), evaporative water loss also appears to decrease.

As expected, in the irrigation treatments used, the more infrequent the reirrigations and the higher the vertical position within containers, the lower the matric potential of the growth medium averaged (Fig. 4). Because the median matric potentials were greater than -6.7 $\mathrm{kPa}$ in all the irrigation treatments and $75 \%$ of the observations were greater than $-18.4 \mathrm{kPa}$ in the driest irrigation treatment $\mathrm{C}$, the water availability for most plants probably would have been adequate (Heiskanen, 1993a, 1995). With seedlings growing in the growth media, however, the growth media below the surface would most likely be drier due to transpiration. In addition, if the surface of peat dries to below
$-80 \mathrm{kPa}$ matric potential, the growth media may become hard to irrigate due to water repellency, especially with the most infrequent irrigations in treatment $\mathrm{C}$ (Heiskanen, 1993c). The dry surface of the peat-perlite mixture absorbed irrigation water more easily and faster than pure peat during the irrigation experiments.

In contrast, the growth medium may become waterlogged with heavy irrigation (Heiskanen, 1995; Lotocki, 1977; Puustjärvi, 1977). For most plants grown in peat growth medium, adequate aeration is considered to occur at air-filled porosities greater than $\approx 40 \%$ (Heiskanen, 1993a, 1995; Puustjärvi, 1975, 1977). According to the water retention characteristics of the media, this limit, on average, was exceeded in all irrigation treatments used (when median matric potentials were less than about $-2 \mathrm{kPa}$ ). However, when shrinkage at

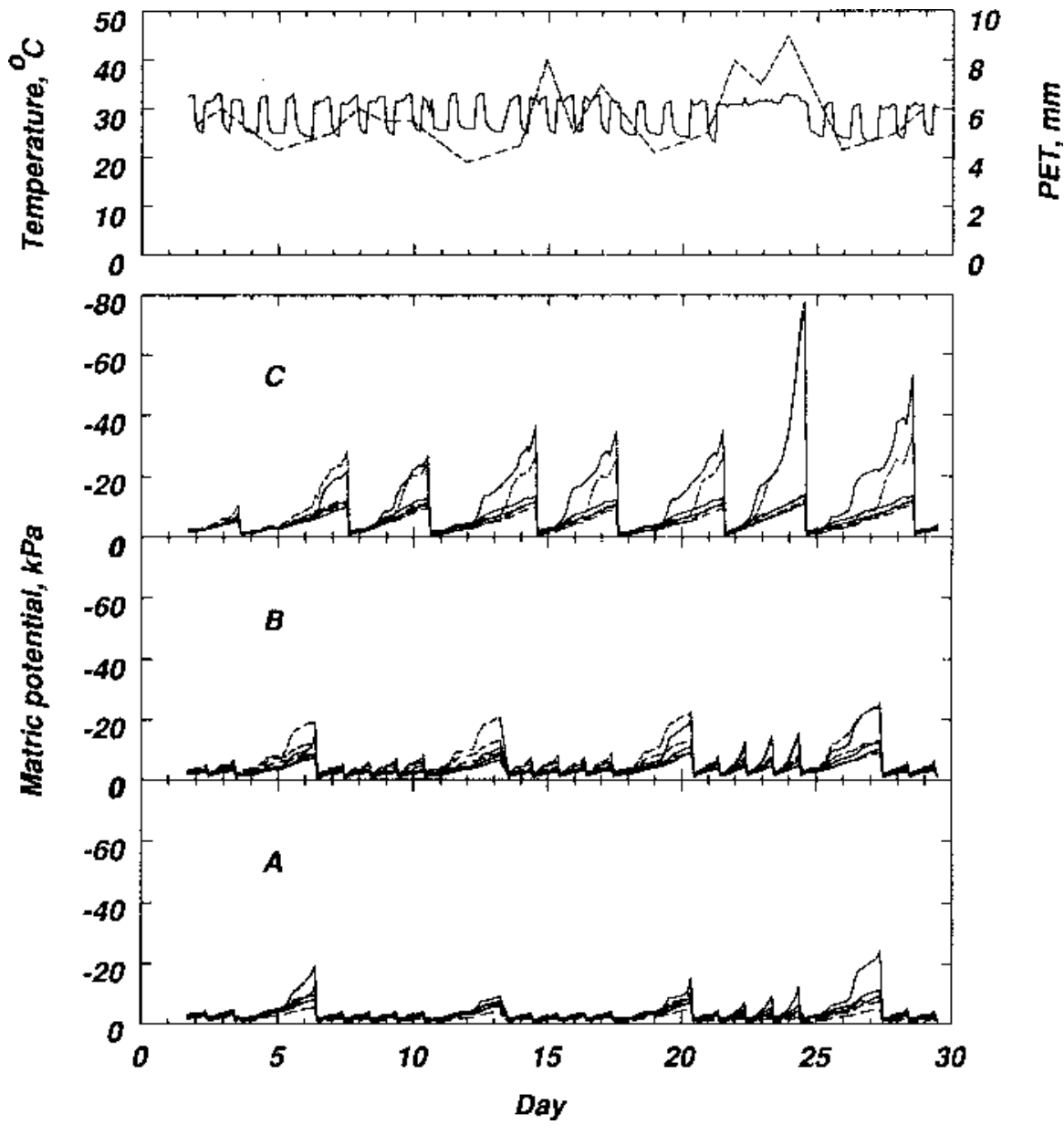

Fig. 2. Temporal matric potential of the growth medium at three levels (each with its own tensiometer) within containers in the three irrigation treatments, where media were slowly hand-irrigated with tap water (A) twice a day, (B) once a day, or (C) twice a week (example taken from the second experiment). Solid lines indicate peat; broken lines indicate peat-perlite mixture. Air temperature (solid line) and daily mean potential evapotranspiration (PET) (broken line) are given in the uppermost graph.

Table 1. Particle size distribution (percent, based on weight) for the growth medium materials used (mean $\pm \mathrm{sD})$. There were three sample replications $(\mathrm{n}=3)$.

\begin{tabular}{lcccrc}
\hline \hline & \multicolumn{5}{c}{ Particle size $(\mathrm{mm})$} \\
\cline { 2 - 6 } Medium & $<0.06$ & $0.06-1$ & $1-5$ & $5-10$ & $10-20$ \\
\hline Peat & $1.7 \pm 0.3$ & $57.1 \pm 3.6$ & $25.9 \pm 2.0$ & $10.5 \pm 2.8$ & $4.8 \pm 5.1$ \\
Perlite & $5.8 \pm 1.1$ & $19.1 \pm 9.4$ & $74.9 \pm 9.7$ & $0.3 \pm 0.4$ & $0.0 \pm 0.0$ \\
\hline
\end{tabular}


desorption is taken into account (Heiskanen, 1993b), the aeration limit was encountered at somewhat lower matric potentials (approximately more than $-4 \mathrm{kPa}$ for peat and more than $-2 \mathrm{kPa}$ for the peat-perlite mixture). Therefore, average matric potentials that yield inadequate aeration may have prevailed for peat in irrigation treatments $\mathrm{A}$ and $\mathrm{B}$ within the whole container and for the peat-perlite mixture in irrigation treatment A near the bottom of the container (Fig. 4). Thus, especially at low rates of evaporation, using the two most frequent irrigations (A and B) may lead to waterlogging, hence hypoxia, for plants grown in containers. However, especially at high evaporation rates, excess water in a growth medium may be transpirated rapidly by the plants.

The great water retention in peat at desorption affects the suitability of the irrigation methods. If peat is irrigated frequently with relatively small quantities of water, all the water may be retained in only the upper part of the medium, while the lower parts of the container remain dry. The amount of water actually received by the medium also may be reduced greatly due to interception by foliage. The intercepted water is lost by evaporation, especially when plants are irrigated with a very fine mist of water and the evaporation rate is high (Landis et al., 1989). Transpiration of growing plants may decrease the water content in the lower parts of the container further. In addition, the moist peat surface may promote growth of algae and mosses (Cronberg, 1991; Tinus and McDonald, 1979), which may block the pores of the peat structure and hence restrict aeration of the medium. Too frequent irrigation may thus be accompanied by inadequate availability of water and $\mathrm{O}_{2}$ for plants. Therefore, although the average aeration limit would be exceeded temporarily, low-humified peat medium may require relatively infrequent reirrigations, during each of which a sufficiently large quantity of water should be applied within a short time (Heiskanen, 1995; Puustjärvi, 1977; cf. Langerud and Sandvik, 1991). However, due to their lower water retention capacity, small containers require more frequent irrigation than large ones (Heiskanen, 1995; Langerud and Sandvik, 1991). Nevertheless, excess drying should be avoided to prevent too great a decrease in water availability and surface crusting and unwettability of peat (about $-80 \mathrm{kPa}$ at the peat surface), which causes difficulties in irrigation (Heiskanen, 1993c). Matric potentials higher than about $-80 \mathrm{kPa}$ in the peat surface also are likely to provide moderate water availability to seedlings in the root zone. Although maximum growth is not achieved, moderate water stress improves quality and hardiness in conifer seedlings (Blake et al., 1979; Landis et al., 1989).

Light, low-humified, sphagnum peat growth medium retains water readily, but with increasing frequency of reirrigations, it also provides faster evaporation. Compared with the peat-perlite mixture, pure peat retains more water at desorption and hence provides greater water availability for plants grown with infre-

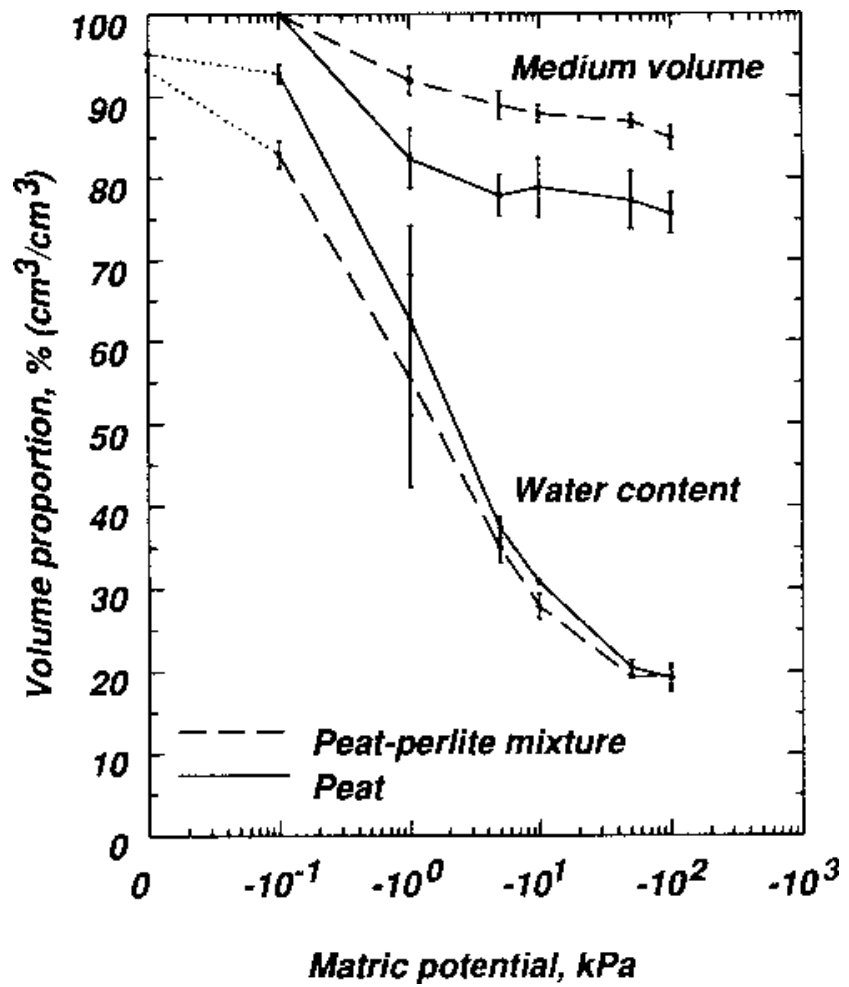

Fig. 3. Water retention characteristics and volume at desorption for the growth media used. Vertical lines indicate SD. There were three sample replications $(n=3)$.

Table 2. Mean daily evaporation (in millimeters) from containers filled with the growth media (range in parentheses). The corresponding mean evaporation from free water was $5.3 \mathrm{~mm}(3.0-9.0)$. There were three containers within an irrigation treatment $(\mathrm{n}=3) . P$ values were determined by one-way analysis of variance.

\begin{tabular}{lcccc}
\hline & \multicolumn{4}{c}{ Irrigation treatment $^{\mathrm{z}}$} \\
\cline { 2 - 5 } Medium & $\mathrm{A}$ & $\mathrm{B}$ & $\mathrm{C}$ & \\
\hline Peat & $6.9(3.6-8.9)$ & $6.2(4.0-8.9)$ & $5.0(3.9-6.5)$ & $P<0.0001$ \\
Peat-perlite & $6.5(3.3-8.6)$ & $5.7(3.7-8.2)$ & $4.7(3.4-6.5)$ & $P<0.0001$ \\
& $P=0.0747$ & $P=0.0540$ & $P=0.3508$ & \\
\hline
\end{tabular}

${ }^{2}$ Treatments were irrigated as follows: $\mathrm{A}=$ twice a day, $\mathrm{B}=$ once a day, or $\mathrm{C}=$ twice a week.

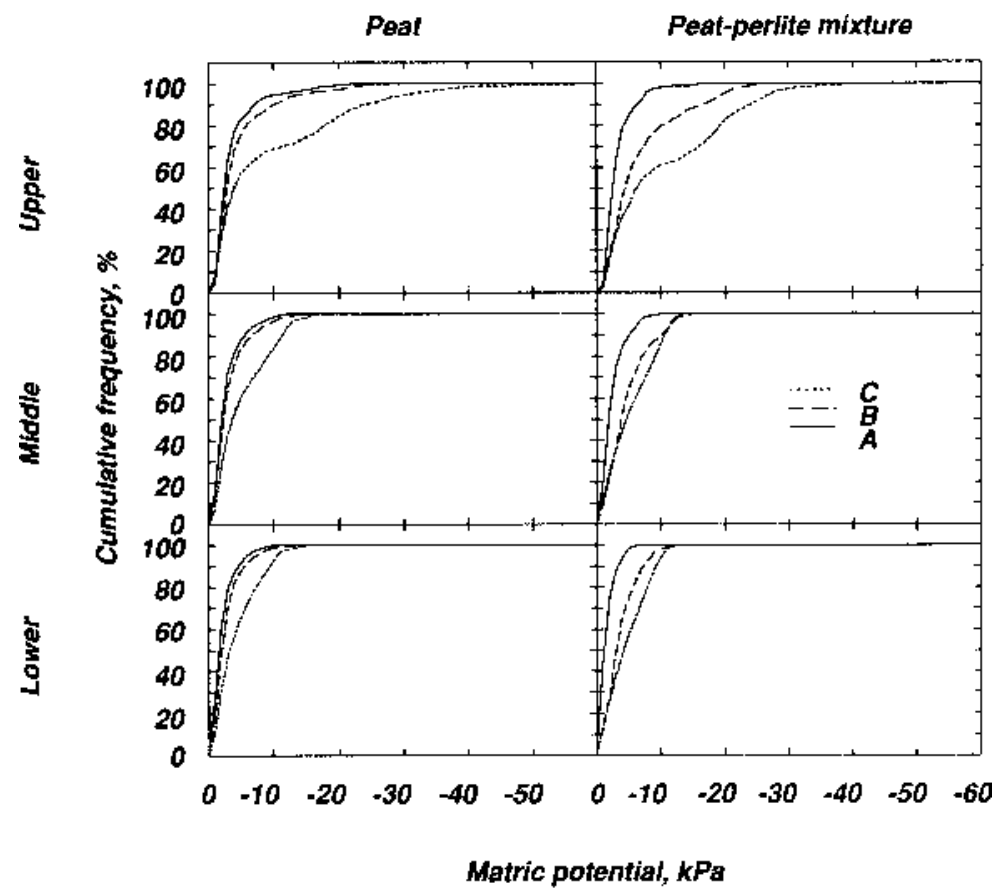

Fig. 4. Cumulative frequency (percent) for the matric potential of the growth média in containers at the irrigation treatments used. The frequency used is from the occurrence of matric potential every second hour during the irrigation experiments. 
quent irrigation. When the surface of the growth medium is dry, however, peat-perlite mixtures have better rewettability. When frequent reirrigations to container capacity are used, adding perlite to peat is better than using peat alone because the waterlogging risk and decrease in $\mathrm{O}_{2}$ availability is lowered due to the lower water retention and higher air-filled porosity of a peat-perlite mixture in wet conditions. To prevent uneven vertical water distribution within containers, waterlogging, and excess evaporation, low-humified peat requires relatively infrequent irrigation with sufficient water applications given within a short period. By using these infrequent reirrigations, costs may be lowered due to a reduction in the amount of watering, monitoring, and work load required.

\section{Literature Cited}

Blake, J., J. Zaerr, and S. Hee. 1979. Controlled moisture stress to improve cold hardiness and morphology of Douglas-fir seedlings. For. Sci. 25:576-582.

Cronberg, N. 1991. Åtgärder för kontroll av lungmossa i planteskolemiljö (in Swedish). Swedish Univ. of Agr. Sci., Dept. of For. Regeneration, Garbenberg, Plantnytt. 6:1-4.

Day, R.J. 1980. Effective nursery irrigation depends on regulation of soil moisture and aeration, $\mathrm{p}$. 52-71. Proc. North Amer. For. Tree Nursery
Soils Wkshp., 28 July-1 Aug. 1980, Syracuse, N.Y.

Heiskanen, J. 1993a. Favourable water and aeration conditions for growth media used in containerized tree seedling production: A review. Scandinavian J. For. Res. 8:337-358.

Heiskanen, J. 1993b. Variation in water retention characteristics of peat growth media used in tree nurseries. Silva Fennica 27:77-97.

Heiskanen, J. 1993c. Water potential and hydraulic conductivity of peat growth media in containers during drying. Silva Fennica 27:1-7.

Heiskanen, J. 1995. Irrigation regime affects water and aeration conditions in peat growth medium and the growth of containerized Scots pine seedlings. New For. (In press.)

Heiskanen, J. and J. Laitinen. 1992. A measurement system for determining temperature, water potential and aeration of growth medium. Silva Fennica 26:27-35.

Landis, T.D., R.W. Tinus, S.E. McDonald, and J.P. Barnett. 1989. Seedling nutrition and irrigation. The container tree nursery manual. vol. 4 . For. Serv., U.S. Dept. of Agriculture, Washington, D.C. Agr. Hdbk. 674.

Langerud, B.R. and M. Sandvik. 1991. Transpiration of containerized Picea abies seedlings grown with different irrigation regimes. Scandinavian J. For. Res. 6:79-90.

Lotocki, A. 1977. Effect of root aeration and form of nitrogen on photosynthetic productivity of Scots pine (Pinus sylvestris L.). Acta Soc. Bot. Poloniae 46:303-316.

McDonald, S.E. 1984. Irrigation in forest-tree nurs- eries: Monitoring and effects on seedling growth, p. 107-121. In: M.L. Duryea and T.D. Landis (eds.). Forest nursery manual: Production of bareroot seedlings. Martinus/Junk Publishers, The Hague, The Netherlands.

Puustjärvi, V. 1975. The effect of air space in the peat substrate on yield of greenhouse products. Peat \& Plant Yrbk. 1973-75:15-16.

Puustjärvi, V. 1977. Peat and its use in horticulture. Turveteollisuuslitto ry. Publication 3. Liikekirjapaino, Helsinki.

Rikala, R. 1985. Estimating the water requirements of containerized seedlings on the basis of evaporation (in Finnish with English summary). Folia For. 627:1-18.

Timmer, V.R. and G. Armstrong. 1989. Growth and nutrition of containerized Pinus resinos a seedlings at varying moisture regimes. New For. 3:171-180.

Timmer, V.R. and B.D. Miller. 1991. Effects of contrasting fertilization and moisture regimes on biomass, nutrients and water relations of container grown red pine seedlings. New For. 5:335-348.

Tinus, R.W. and S.E. McDonald. 1979. How to grow tree seedlings in containers in greenhouses. Rocky Mt. For. and Range Expt. Sta., For. Serv., U.S. Dept. Agr. Gen. Tech. Rpt. RM-60.

Vakkilainen, P. 1982. On the estimation of evapotranspiration (in Finnish with English summary). PhD Diss., Univ. of Oulu, Finland Acta Univ. of Oulu C 20. Artes Constr. 6.

White, J.W. and J.W. Mastalerz. 1966. Soil moisture as related to "container capacity." J. Amer. Soc. Hort. Sci. 89:758-765. 